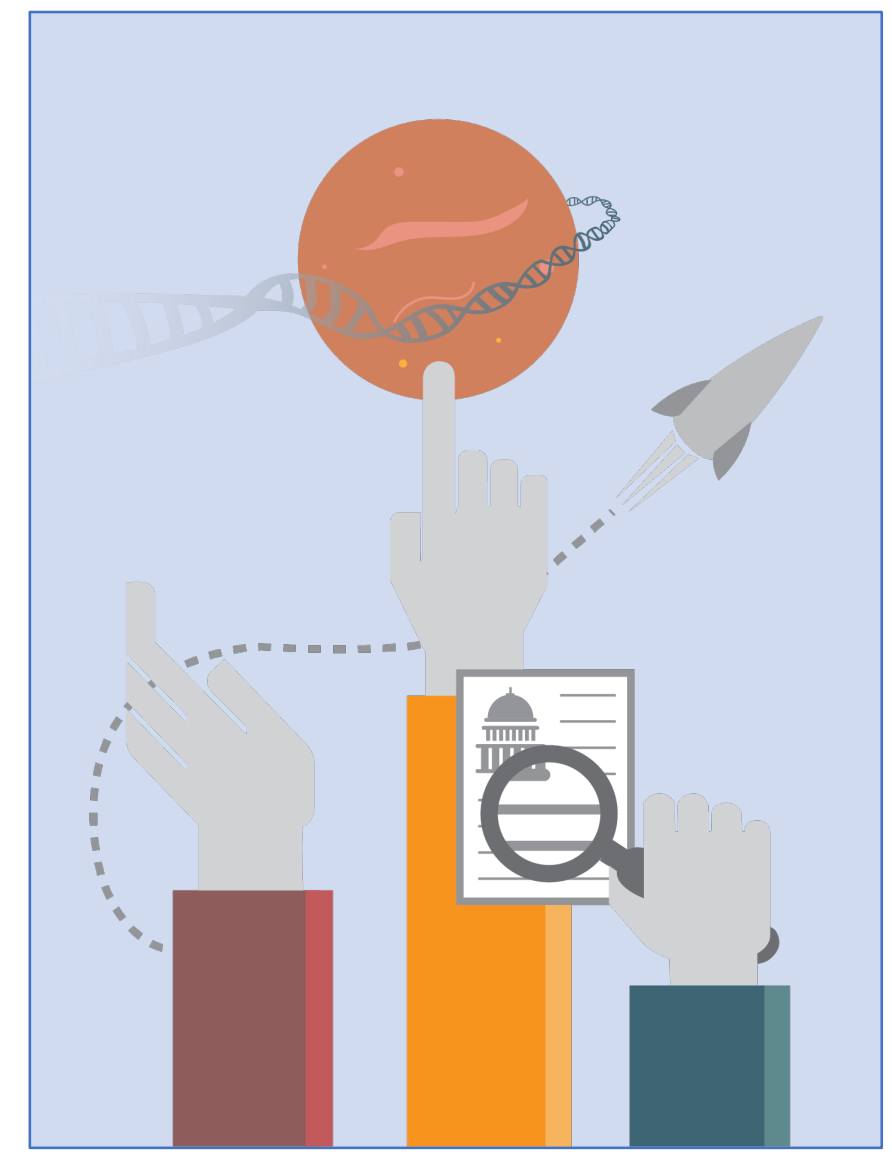

\title{
Collaborative Partnerships for Improved Astrobiology Science Outcomes
}

\section{Lead Author:}

Heather V. Graham

\section{Co-Author:}

Alison Murray

\section{Endorsed by:}

Sushil Atreya Jason Dworkin

Tori Hoehler

Sarah Stewart Johnson

Betül Kaçar

Ramanarayanan Krishnamurthy

Victoria Meadows

Nilton Renno

Frances Westall
Catholic University of America/NASA GSFC

Desert Research Institute

University of Michigan

NASA Goddard Space Flight Center

NASA Ames Research Center

Georgetown University

University of Arizona

The Scripps Research Institute

University of Washington

University of Michigan

Centre National de la Recherche Scientifique-Orleans 


\section{EXECUTIVE SUMMARY}

In this white paper, we describe current partnerships relevant to the NASA Astrobiology Program, identify those that could be improved or strengthened, and detail potential new public-private partnerships or collaborations.

NASA-sponsored astrobiology research focuses on the basic questions: How does life begin and evolve? and Does life exist elsewhere in the Universe? The NASA Astrobiology Program funds basic research that contributes to meeting science mission goals. The NASA Astrobiology Program also supports education and training opportunities for the scientific community as well as public engagement and outreach. NASA has a number of critical partnerships with other national and international agencies, private companies, and independent foundations contributing to the goals of the NASA Astrobiology Program by supporting astrobiology research, technology development and engaging in education and public outreach.

Collaborations with commercial partners can be improved and expanded where there is overlap in NASA and the potential partner's goals. Other federal agencies have established programs that allow for promising research proposals to be matched up with external philanthropic foundations that allow for private-sector funds to support research and projects that further the goals of these agencies and serve the public interest. Partnerships with non-profit institutions could allow for collaborative use of resources to further astrobiology research. Both of these types of partnerships could be leveraged for the NASA Astrobiology Program. The NASA Astrobiology Program can take a more active role in seeking out such partnerships with private organizations with objectives in sync with NASA's mission. Finally, essential improvements between NASA and NOAA's Office of Ocean Exploration and Research program and the NSF's Office of Polar Programs could provide significant benefit to new NASA missions in the next decade - particularly those to Ocean Worlds, which have new astrobiology-related measurement and instrumentation requirements in addition to technology developments (e.g. subsurface exploration).

\section{NASA ASTROBIOLOGY FUNDING PROFILE}

The NASA Astrobiology Program solicits research proposals from the broad scientific community in order to advance the Agency's strategic goals. The NASA Astrobiology Program allocates funding through a variety of means (Figure 1). Approximately $60 \%$ of NASA Astrobiology Program funds go towards basic research through the Exobiology, Habitable Worlds, and Emerging Worlds research and analysis (R\&A) programs and large research teams previously managed by the NAI (NASA Astrobiology Institute) and in transition to

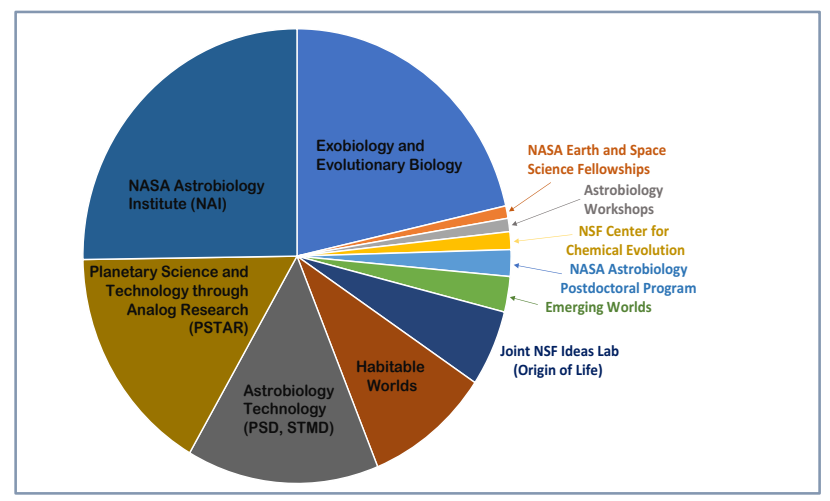

Figure 1: Typical annual allocations of astrobiology funds support basic research, technology, and development for off-world exploration in 2016. 
be managed through the Interdisciplinary Consortium for Astrobiology Research (ICAR). On an average annual basis, the large NAI/ICAR teams supports over 300 researchers, over 75 postdoctoral fellows and over 150 graduate students across more than 150 institutions.

The NASA Astrobiology Program also supports instrument development through the Astrobiology Technology Program and Planetary Science for Technology and Analog Research (PSTAR) a joint science-technology program that supports field research projects including a technology and/or operational advancement component. Approximately $7 \%$ of NASA Astrobiology Program funds are allocated to the joint NSF/NASA astrobiology Ideas Lab and Center for Chemical Evolution (CCE). The remaining funds are used to support early career scientists through the Earth and Space Science Fellowships program and the NASA Astrobiology Postdoctoral Program and to further community engagement in setting research priorities through Astrobiology Workshops.

\section{CURRENT STATUS OF NASA ASTROBIOLOGY PARTNERSHIPS}

Partnerships between federal agencies and other entities, both public and private, offer unique, collaborative advantages. The NASA Astrobiology Program has a tradition of partnering with universities, foundations, and businesses as well as other federal agencies and foreign government bodies by means of a variety of agreements. A partnership can be designed to advance mutually beneficial research goals. Constructing partnerships that are beneficial to all parties and yields successful results is a challenge, yet public-private partnership can significantly advance the goals of the NASA Astrobiology Program while reducing cost, expanding knowledge, and sharing resources. What follows is a summary of some of the NASA Astrobiology Program's current prominent public-private partnerships. Astrobiology partnerships include collaborations with universities and non-profit private foundations and institutions, interagency and commercial arrangements as directed by Space Act Agreements, and collaborations with international partners.

\section{Academic and Non-profit Partnerships}

Currently, the NASA Astrobiology Program funds hundreds of researchers at academic and nonprofit institutions through a competitive process. The majority of basic research spending by the NASA Astrobiology Program goes to these researchers, who are supported by research and analysis grants or by NAI cooperative agreements. In 2015, the NAI alone supported 295 researchers, 63 postdoctoral fellows and 128 graduate students across 124 institutions. In addition to funding academic laboratories and staff, the NASA Astrobiology Program has also provided funding to non-profit research branches of university systems including the Desert Research Institute (part of the Nevada System of Higher Education) and the Carl Sagan Institute at Cornell University. Non-profit research facilities founded by private foundations have also received support from the NASA Astrobiology Program. Approximately 10 percent of NASA Astrobiology Program funding is awarded annually to private non-profit institutions, such as the Carnegie Institutes of Washington, the SETI Institute, and the Santa Fe Institute. 


\section{Foundation Support for Astrobiology}

Many private foundations further the goals of the NASA Astrobiology Program by also funding astrobiology research at universities, NASA centers, and private research institutions, including but not limited to the John Templeton Foundation, the Simons Foundation, the Alfred P. Sloan Foundation, the Whitehall Foundation, the Howard Hughes Medical Institute, the MacArthur Foundation, the Moore Foundation, and the Agouron Institute. The most common form of foundation support is grant funding issued through a competitive proposal process. These grants are analogous to those provided by the NASA Astrobiology Program. However, foundation funds can often be more flexibly applied to capital laboratory improvements, travel and field research expenses, or salaries and stipends. Given current restrictions on outside funding of NASA centers or civil servants, partnership options between NASA and private foundations are limited. Nevertheless, the Simons Collaboration on the Origin of Life has supported basic research at the Astrobiology Analytical Laboratory, which is located at NASA Goddard Space Flight Center and is dedicated to the study of extraterrestrial materials. Most foundations do not host research facilities, however, the Simons Foundation has offered computational support to astrobiology research through its scientific computing facility. While the Agouron Institute does not house research facilities, it offers summer field trips for students to sites of astrobiological importance.

\section{Interagency and Domestic Commercial Space Act Agreements and Partnerships}

In support of its mission, NASA regularly partners with industry; academia and nonprofits, and government agencies at the federal, state, and local levels, as well as international entities. NASA's external partnerships function as a key component of the Agency's operating model and are instrumental in supporting NASA's strategic plan and Agency objectives. Commercial partnerships in the NASA Astrobiology Program focus on basic and applied research in science and engineering, the results of which are published and shared broadly within the scientific community. Basic research is distinct from proprietary research and from industrial development, design, production or product utilization, the results of which ordinarily are restricted for proprietary or national security reasons. By supporting the development and utilization of new knowledge and technologies by its domestic partners, NASA improves America's industrial supply chain, maximizes U.S. taxpayers' return on investment in NASA, and harnesses the flexibility of private-sector approaches to develop and commercialize technology.

NASA is well known for technological innovation, and this is an area where many entities may be interested in partnering with NASA. Innovation may or may not be the goal of a NASAfunded project from the onset, but results often can be found useful by the commercial sector. The technology development, reporting, and transfer process begins with technology, which can be sponsored by any one of the NASA Mission Directorates, and can be developed at any of the NASA Centers or outside the Agency. Technology can also be developed by industry through contracts (for example, Small Business Innovative Research (SBIR) awards). There are many potential forms of partnership to explore beyond traditional aerospace industry partnerships that would benefit astrobiology research. These partnerships could leverage advances and best practices in specialized analytical instrumentation, autonomy, and other fast developing 
technology sectors. NASA's SBIR program has made astrobiology-relevant awards in recent years.

\section{Participating-Scientists and International Research Partnerships}

Finding qualified partners to advance the NASA Astrobiology Program's research goals sometimes requires the program to look beyond U.S. borders. NASA welcomes proposals from non-U.S. organizations (with the exception of China) and proposals that include the participation of non-U.S. co-investigators (Co-Is). However, foreign entities are generally not eligible for funding and must propose to participate in research programs without an exchange of funds. This policy applies even to research performed by non-U.S. organizations included on proposals submitted by a U.S. organization. In these cases, proposals must include a statement by the PI or Co-I institution accepting responsibility for the cost of the research proposed, should the proposal be selected by NASA.

Through NASA Participating Scientist programs, the NASA Astrobiology Program provides direct funding for individual scientists to collaborate on missions in cases where they are not members of the mission's science team. Participating Scientists are competitively selected through NASA Research Announcements and are not open to non-U.S. citizens. Participating Scientists may work on missions operated by NASA or other national space agencies. For example, U.S. citizens at academic institutions, as well as civil servants, have received funding to operate as Participating Scientists on JAXA missions (Akatsuki, Hayabusa-2) as well as ESA missions (Venus Express). Similarly, some of NASA's international partner agencies offer similar funding programs for non-U.S. citizens to participate in research on NASA missions.

\section{SUGGESTIONS FOR IMPROVING FUTURE PARTNERSHIPS}

In order to improve potential partnerships between the NASA Astrobiology Program and the previously described entities we propose five recommended courses of action. Some of these would require congressional action as well as agency organization.

\section{Scientific Support for Secondary Funding Sources}

A core contribution that the NASA Astrobiology Program provides to the research community is the oversight and organization of an exceptional proposal solicitation and peer-review process. Seasoned program and discipline scientists assemble specialists in myriad fields to examine research proposals submitted in response to announcements that reflect the gaps in our understanding and research needs for upcoming missions. Proposals are heavily scrutinized by experts and generalists to ensure that selected projects are of the highest quality, technically feasible, and thematically relevant. Other agencies have leveraged the peer review process to provide expertise for a marketplace of secondary funders - generally philanthropic organizations or private research foundations. By providing peer review as a product to these institutions, Federal agencies are able to extend the value of the review process and potentially provide access to other sources of funding for meritorious projects that are not selected for Federal funding due to limited budgets. 
Notable examples of these public-private partnerships include:

- Basic Research to Enable Agricultural Development (BREAD), a National Science Foundation partnership with the Bill and Melinda Gates Foundation that directs funding to researchers seeking science-based solutions to problems concerning smallholder agriculture in developing countries;

- The Accelerating Medicines Partnership, involving the National Institutes of Health, the U.S. Food and Drug Administration, ten biopharmaceutical companies, and multiple nonprofit organizations, which provides funding for the development and validation of novel diagnostics and treatments in the areas of juvenile diabetes, cancers, and muscular dystrophy;

- The U.S. Department of Education Investing in Innovation (I-3) program, which directs funding to local educational agencies, school consortiums, and nonprofit organizations seeking innovative approaches to improving student achievement in low-performing schools and supporting effective teachers and principals.

These programs offer mechanisms by which the NASA Astrobiology Program could direct worthy research proposals that cannot currently be supported to appropriate external funders, thereby enhancing astrobiology research goals, engaging with the philanthropic community, and expanding support for worthwhile research.

\section{Joint Coordination for NASA-funded Oceanography Research}

Water in our Solar System exists in diverse forms on moons, dwarf planets, and even comets. Oceans on other worlds offer clues in the quest to discover life beyond our home planet, a current priority in the NASA Astrobiology Program. One component of that research is exploring the Earth's ocean and uncovering its mysteries. While there are research projects that would be selected through NASA's competitive award programs, the limited capacity of the research fleets operated by NOAA and the NSF creates a barrier to the resources available to complete those projects. Two non-profit research institutions, the Ocean Exploration Trust and the Schmidt Ocean Institute have offered to provide shipboard services for research expeditions funded by the NASA Astrobiology Program. These proposed partnerships would offer NASAfunded principal investigators a choice of two research vessels to work on and would allow for both the NASA Astrobiology Program and these organizations to each further their goals. This type of partnership requires an agreement that allows such services to be provided to NASA Astrobiology PIs and coordinated as part of the selection process.

\section{A Bold Proposal: The NASA Astrobiology Foundation}

A valuable form of public-private partnership that has allowed other Federal agencies to fully engage philanthropic nonprofits is the "Agency Foundation". These entities operate independently from the agency and serve to direct both Federal and non-Federal funds to research that is of particular interest to both partners. Federal agencies that have established foundations to partner with non-governmental entities include the National Institutes of Health, the Centers for Disease Control, the U.S. Department of Agriculture, and the Food and 
Drug Administration. An Act of Congress would be necessary to establish a NASA foundation. A NASA Foundation for Astrobiology research would allow the NASA Astrobiology Program to further advance its research goals leveraging the resources of non-governmental entities. Additionally, such a Foundation could further astrobiology research objectives that are not currently in line with NASA's mission priorities but may be of interest to private entities, such as translational research similar to the Moore Foundation's efforts.

Improved Commercial Arrangements to meet Scientific Challenges

Public-private partnerships offer many cost, expertise, and resource-sharing opportunities. Successful public-private partnerships require joint planning, joint contributions, and shared risk. NASA publicizes commercial partnership opportunities through several channels, including:

- https://www.nasa.gov/partnerships.html Includes information about partnering opportunities with each NASA Center

- https://www.nasa.gov/partnerships/opportunities.html Includes information about current partnership opportunities

- https://www.fbo.gov Includes information about current opportunities for all Federal Agencies

These forms of reaching out to potential partners have been effective, but a more active approach at recruiting potential partners could expand both the types and numbers of partnerships available to NASA in general and the NASA Astrobiology Program in particular. Since most of the NASA Astrobiology Program's interactions are with academia, a more direct approach to seeking partnerships with commercial entities - either through "grand challenge" activities or targeted requests - could open new avenues of collaboration. New partnership mechanisms like the Frontier Development Lab - a partnership involving NASA and a variety of private sector entities that applies machine learning techniques to science challenge goals - may prove promising.

\section{Improvements To the Polar Program Partnership}

The NASA Astrobiology Program and the Science Mission Directorate as a whole, participate in Interagency Agreements in which NASA is both a service provider and a service recipient. An example is the Polar Programs partnership between the NASA Astrobiology Program and the NSF. By Executive Order, the NSF must coordinate logistical support for any agencies that fund and undertake scientific activities in Antarctica. Any U.S. researcher wishing to gain access to the continent's unique field sites, which play an important role in astrobiology research, are obligated to purchase necessary assistance from the NSF and its chosen contractors. While the intent of this order is to reduce redundancy in spending on these expeditions, the order has resulted in often higher prices or for non-NSF agencies as well as inconvenient restrictions.

A 2003 NASEM study "Life in the Universe: An Assessment of U.S. and International Programs in Astrobiology" advised that the NSF and NASA "engage in a detailed study of the desirability of and the means by which the two agencies can create joint programs in astrobiology". It is clear 
this action is very necessary with respect to astrobiology research, especially given that SMD Astrobiology programs are currently not supporting field research in Antarctica. Support is necessary to provides access to unique field locations which are unmatched on earth (e.g. the frigid polar deserts found in the McMurdo Dry Valleys), and are of particularly critical value to the next generation of missions to the outer solar system. Studies in Antarctica are needed to develop mission-driven benchmarks for biosignature measurement requirements in the most relevant analogs available to science, to best understand how biosignatures can be preserved for millions of years in icy habitats, to study combined effects of environmental stresses found in 3-4 km deep ice sheets, to understand the evolution of life in subglacial ecosystems and in the permanently dark waters below $1 \mathrm{~km}$ thick ice shelves. A new vision for a sustainable partnership between NASA and NSF is needed for the next decade, on that would provide $a$ dedicated pool of funding dedicated to maintaining Antarctic access and financing overhead costs for these activities, ensuring that all science missions there are well served.

\section{Building effective partnerships: Lessons from other agencies}

Many NSF programs have sought to develop new ways of building effective partnerships with philanthropic foundations, and while some foundations support basic research they establish their own research goals and tend to focus on specific areas of research support. In contrast, the goals and objectives of Federal research agencies are established by Federal statue and national policy in accordance with guidance from the National Academies. A report from the 2015 Workshop on Collaborations between the NSF/MPS and Private Foundations provides an apt summary of this difference: "As a new generation of private benefactors turn their attention to science funding, concerns have been articulated ... that the nation's scientific agenda could be distorted by the idiosyncratic preferences of a handful of billionaires".

\section{CONCLUSIONS}

The NASA Astrobiology Program funds basic research that contributes to meeting science mission goals and objectives towards these goals. The majority of the program's budget goes to funding PIs and their teams at universities and nonprofit institutions to conduct astrobiology research. Currently, the NASA Astrobiology Program public-private partnerships include collaborations with universities and non-profit private foundations and institutions, interagency and commercial arrangements as directed by Space Act Agreements, and collaborations with international partners. The NASA Astrobiology Program should explore the mechanisms detailed here to make these collaborations easier to engage in and more advantageous to all parties. Specifically, the program should consider directing worthy research proposals that cannot currently be supported to appropriate external funders, jointly collaborate with philanthropic organizations with resources necessary for astrobiology research, and utilizing a yet-to-be-created NASA Foundation. In addition, the Program should strengthen the relationship with potential private partners with complementary objectives through mechanisms similar to the Frontier Development Lab and workshops similar to the Ideas Lab, to maximize scientific return on investment. 